\title{
Collective Memory and the Rhetorical Power of the Historical Fiction Film
}

\author{
CARL PLANTINGA
}

\begin{abstract}
As tools to establish collective memory, historical fiction films either connect or don't connect with audiences depending on the historical context in which they are seen. It also makes sense, however, to account for their function psychologically as prompts for experience. In that regard, at least the following three sources account for their rhetorical power. First, for most viewers, they have an ambiguous reference to historical reality that puts into play the "sleeper effect," which inhibits counterarguing and thus promotes the establishment of historical memory. Second, historical fiction films are mass media disseminated widely to millions of viewers. They also possess medium characteristics that foster viewer immersion and a sense of "presentness." Third, the ritualized use of conventional narrative schemas elicits emotions that assist memory formation. To make these points, I draw on both media theory and social science research. I give examples and analyze scenes from films such as Selma (2014), Lincoln (2012), and BlacKkKlansman (2018) to illustrate my points. Finally, I conclude with a discussion of the ethics of the historical fiction film, arguing that a blanket dismissal of mainstream historical fictions would be wrong, for it would deny the possibility of establishing beneficial collective memories that have to do, for example, with antiracism or other values that should be widely embraced.
\end{abstract}

Keywords: historical fiction film, docudrama, collective memory, sleeper effect, mainstream narrative

In 1965, the Rev. Martin Luther King Jr., a Christian pastor and African American civil rights leader, led a group of activists on a five-day, fifty-four-mile march from Selma to Montgomery, Alabama, to publicize the obstacles facing black voters and to promote the need for a national voting rights act. The march was especially dramatic because previous attempts by the marchers had been met by violence, made famous by news photographs of police using batons, teargas, and dogs against protesters. By the time 
the marchers reached Montgomery, their numbers had swelled to twenty-five thousand people.

Like all historical events, this march had a multiplicity of possible meanings. Meaning is not usually obvious when an event initially occurs and meaning is contested as it develops. ${ }^{1}$ This march occurred in the midst of a civil rights movement that divided Americans on issues of race and human rights. Was the march a courageous stand for equal voting rights or an unwelcome challenge to white privilege? Would this march lead to meaningful change? Would it become an icon of the civil rights movement or would it be forgotten? Meanings themselves change over time, even after they have been congealed or solidified. Meanings are thus continually negotiated. Will this march remain a part of the fabric of US collective memory and public imagination? And, if so, how might that happen?

A historical fiction film, backed by a multimillion-dollar marketing and advertising campaign, and through the employment of cinematography, mise-en-scène, star power, dramatic music, and intense and emotional storytelling may become a powerful force in the process by which this meaning is interpreted, focused, and sedimented in a particular culture. For this reason, Ava DuVernay's 2014 film Selma, which provides a powerful account of the civil rights march from Selma to Montgomery, and which puts the march into a clear ideological framework, is a powerful force in the formation and preservation of collective memory.

The effect of historical fiction films, whether intended or not, is to create, change, and/or preserve the collective memory of a people or nation. ${ }^{2}$ How do they accomplish this task? How do historical fictions contribute to cultural mythmaking and collective memory? There is no simple answer to this question, of course. The sociocultural conditions into which the film is introduced are central. The impact of the film depends on who sees it, the circumstances in which it is seen, and how it is later used and invoked. This essay, however, focuses on a different aspect of the answer to this question, an equally important though partial account of the power of historical fiction. This essay focuses on the kind of embodied cognitive experience that historical fictions offer to viewers and how that contributes to the formation of collective memory. It also details the most salient tools and technologies by which collective memory is created, sedimented, preserved, ritually shared, and passed on through the work of historical fiction film.

My claim here is that as tools of collective memory, historical fiction films derive their persuasive power from at least these three sources: (1) an ambiguous reference

1. At the time of this writing, for example, the meaning of the Black Lives Matter movement is being hotly contested across the United States.

2. By film here I mean a work in any of the moving-image media, from theatrical films to television programs to shows that stream on the Internet. 
to historical reality, (2) medium characteristics that foster viewer immersion and a sense of "presentness," and (3) the use of conventional narrative schemas that elicit emotions that assist memory formation. I draw examples and analyze scenes from films such as Selma, Lincoln (2012), and BlacKkKlansman (2018) to illustrate my points.

I conclude with a consideration of the ethics of the mainstream historical fiction film, arguing that rather than condemning such films tout court, we should consider them on a case-by-case basis and remain open to their possible benefits. As Miriam Hansen argues in her assessment of the radically different critical responses to Schindler's List and Shoah, the maintenance of a strict opposition between "bad" mainstream and "good" modernist cinema "does not yield a productive way of dealing with either the films or the larger issues involved." 3 Similarly, a blanket rejection of mainstream historical fictions for their supposed deleterious effects would be premature.

\section{Historical Fiction and Collective Memory}

By historical fiction film I mean fictionalized accounts of history in a moving-image medium that purport to tell a more or less true story about, or provide a historically more or less accurate account of, some element of the past. The point is that all of these films are ostensibly based on historical events. This does not mean that viewers understand how closely they adhere to or diverge from the historical record. (Most viewers, as I argue later, are unclear about these issues.) Other terms for historical fiction are docudrama and dramatic documentary, all referring to a somewhat nebulous genre that consists of hybrids of fiction and nonfiction. ${ }^{4}$ Film scholar Steve Lipkin writes that what he terms docudramas "ride the fence" between fictional narrative and documentary, "blending strategies of both, belonging wholly to neither." This hybrid nature, as I later argue, is an important source of the influence of the historical fiction film.

Examples of historical fiction film would include Selma, The Last Emperor (1987), Band of Brothers (2001), The Birth of a Nation (1915), City of Life and Death (2009), BlacKkKlansman (2018), Alexander Nevsky (1938), Schindler's List (1993), Twelve Years

3. Miriam Bratu Hansen, “Schindler's List Is Not Shoah: The Second Commandment, Popular Modernism, and Public Memory," in The Historical Film: History and Memory in Media, ed. Marsha Landy (New Brunswick, NJ: Rutgers University Press, 2001), 201-17.

4. Some might argue that the terms historical fiction film, docudrama, and dramatic documentary name separate genres. While one could perhaps make that argument, such an attempt at precise definitions would bring us too far afield for the purposes of this article. Thus, I will here consider these terms to name a single loosely defined genre.

5. Steve N. Lipkin, Real Emotional Logic: Film and Television Docudrama as Persuasive Practice (Carbondale: Southern Illinois University Press, 2002), x. 
a Slave (2013), Lincoln, Chernobyl (2019), and Goya's Ghosts (2006). Historical fiction films sometimes attain especially powerful cultural significance when they cover issues that become salient due to current events. An example of this is Just Mercy (2019), a film about racial injustice and the exoneration of a black man falsely convicted of murder, which, at the time of this writing, has become an important tool in relation to the Black Lives Matter movement in the United States. Historical fiction films date back to early film history but in the United States, at least, have become increasingly popular since the 1990s.

By collective memory I mean the shared memories of a group about its history and identity. The term collective memory is sometimes used as a synonym for cultural mythology or national imaginary. Strictly speaking, however, the collective memory of a group such as a nation is but one component of that mythology or "imaginary." A cultural mythology, for example, is not simply about the collective memory of the past but also a conception of group identity in the present and a teleology for the future. Some might be inclined to say that collective memories are not necessarily memories at all but can be mythologies of the past. Our memories may be infused with our corporate and individual fantasies (what we would like to believe about the past) or fabrications (such as

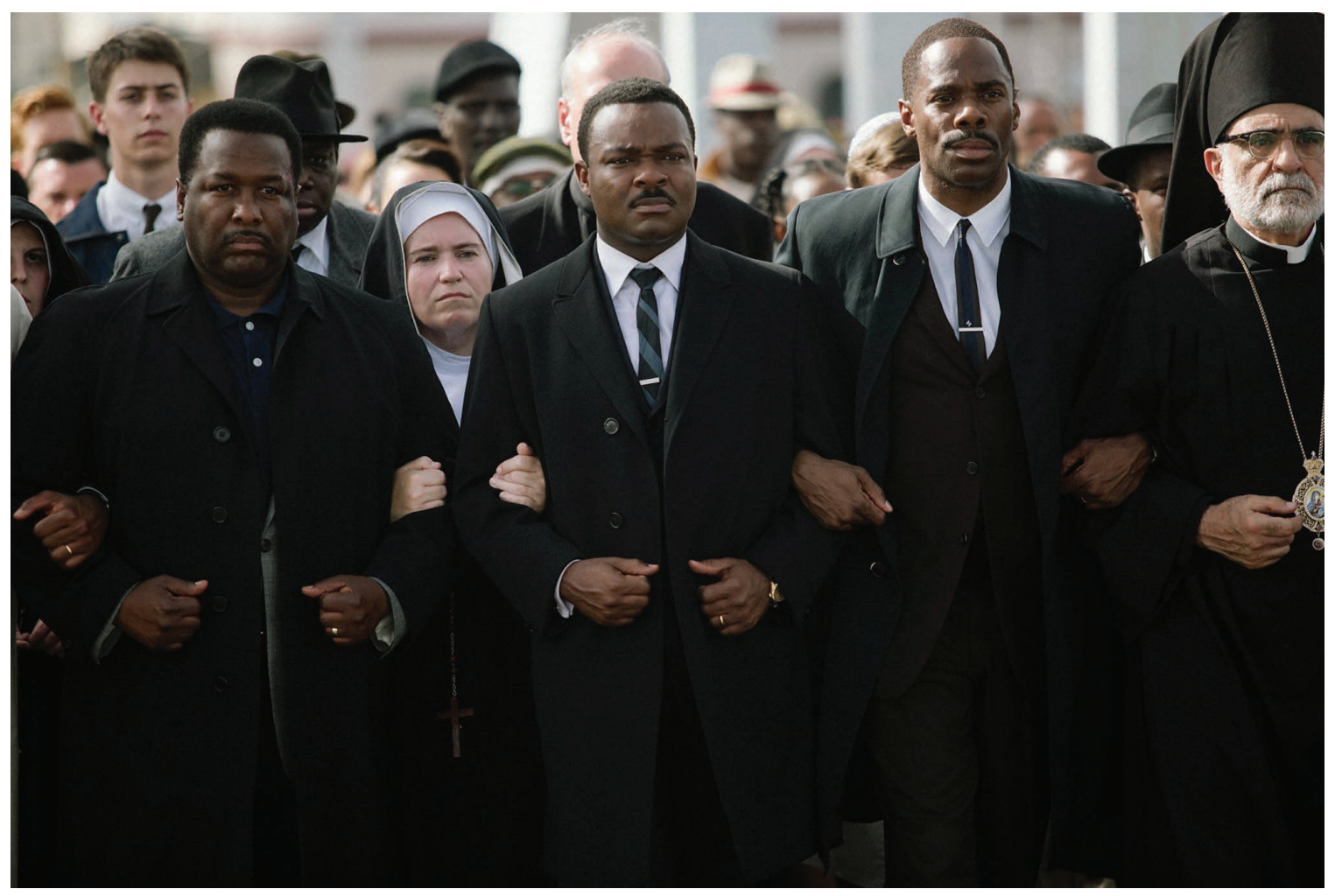

Figure 7.1: Martin Luther King Jr. (David Oyelowo) leads a march for civil rights in Selma (2014). Source: fair use. 
false memories or propaganda that has come to be believed as true). Cultural memory, as Erika Dross puts it, is typically colored "by the fevered pitch of public feelings such as grief, gratitude, fear, shame, and anger." ${ }^{6}$ Both personal and collective memories are like mythologies in that they are often the product of narrative reconstruction and can become something like myth. Memories take the form of narratives, the result of choices among past events—some highlighted, some forgotten—and, most importantly, all are assigned meaning within the narrative patchwork.

Fiction films such as Rebecca (1940), Memento (2000), and Eternal Sunshine of the Spotless Mind (2004) and documentaries such as Waltz with Bashir (2008) and The Act of Killing (2012) highlight the degree to which personal and collective memories (and also the act of forgetting) are in part constitutive of our identities. Collective memories, as they figure within cultural mythologies, are similarly constitutive of the identity of any tribe or affiliation, be it a nation, ethnicity, family, gang, club, political party, or other institution. And while calling this a tribal mythology seems to imply a wholly imaginary construct, that need not necessarily be the case. The march from Selma to Montgomery did actually take place. Yet it is in how the event is narrativized in memory that it takes on its meaning. This is where the controversies and contestations begin.

The makers of historical fictions, either by necessity or artistic license, take liberties with the historical record in narrativizing the events in question. For example, Spike Lee's BlacKkKlansman tells the story of Ron Stallworth, the first-ever African American member of the Colorado Springs, Colorado, police force who sets out to infiltrate the local chapter of the Ku Klux Klan, a racist hate group. The bomb plot foiled in the film, however, was based on an actual KKK bombing from a different time and place, and Patrice (Laura Harrier), who is portrayed as an activist leader and love interest of Stallworth (John David Washington) in the film, is a wholly fictional character. The liberties that most historical fiction makers take with the historical record sometimes generate significant controversy. Thus Selma elicited much discussion about the film's portrayal of US president Lyndon B. Johnson as just as much an antagonist to Martin Luther King Jr. as an ally. ${ }^{7}$

Competing historical accounts are often struggles to establish collective memory. Collective memory is thus a construction and negotiation of group identity through a process of narrativization. As Hanna Meretoja writes, "Memory work is something we do in the present; like narrative, it is an interpretative activity. Instead of simple retrieval

6. Erika Doss, Memorial Mania: Public Feeling in America (Chicago: University of Chicago Press, 2010), 2.

7. Alex Woodson, "Ethics on Film: Discussion of 'Selma," Carnegie Council for Ethics in Public Affairs, August 22, 2016, https://www.carnegiecouncil.org/publications/ethics_onfilm/0018. 
of what is stored in our minds, it is a present activity that is intertwined with a narrative process of meaning-making."

Scholar Alison Landsberg coined the term "prosthetic memory," which she uses to refer to the "deeply felt memory of a past event" through which the person remembering did not actually live. Prosthetic memories, she claims, are powerful, having the capacity to shape a person's "subjectivity and politics." The importance of prosthetic memory has been greatly amplified by mass culture; for example, by monuments, museums, movies, and television. Landsberg is optimistic about the possible ethical and political significance of prosthetic memory, a topic that I will return to later.

The fact that collective memories are like myths does not imply that they are wholly fabrications; this article is not a postmodernist dismissal of truth or accuracy. Like historical fiction films, collective memories can be more or less accurate, more or less comprehensive, and the question of historical accuracy is an important one. It is not the only question however, and it is sometimes overshadowed by the ethical significance of the function of a collective memory in the present. In other words, the role of BlacKkKlansman in establishing or questioning collective memory in the present may be more important than questions about its fidelity to the past. ${ }^{10}$

The process of narrativization lends a certain "value added" to any account of the past. If we distinguish between a chronicle (a mere list of events in chronological order) and a narrative, we can see how this could be the case. As Hayden White argues, the historian must fashion the chronicle into a story, with a discernible beginning, middle, and end; motifs of inauguration, termination, and transition; and a determination of a hierarchy of significance to the recounted events. ${ }^{11}$ Among what is added is valuation - that is, an evaluative perspective, either implicit or explicit. In popular historical fiction film, this evaluative perspective is typically pronounced and explicit.

Narrativization comes in different modes, styles, and genres. Miriam Hansen notes that the classical Hollywood narrative made use of in many mainstream historical fiction films is widely thought to be inadequate to the task of representing complex history. Here she refers specifically to the use of classical Hollywood narrative in

8. Hanna Meretoja, The Ethics of Storytelling: Narrative Hermeneutics, History, and the Possible (Oxford: Oxford University Press, 2018), 33.

9. Alison Landsberg, Prosthetic Memory: The Transformation of American Remembrance in the Age of Mass Culture (New York: Columbia University Press, 2004), 2.

10. Historical divergences that fundamentally alter the meaning of a historical event might be seen as ethically problematic while others that hold little significance for that meaning might be seen as trivial or unimportant.

11. See Hayden White, Metahistory: The Historical Imagination in Nineteenth-Century Europe (Baltimore, MD: Johns Hopkins University Press, 1973); White, Tropics of Discourse: Essays in Cultural Criticism (Baltimore, MD: Johns Hopkins University Press, 1978); White, The Content of the Form: Narrative Discourse and Historical Representation (Baltimore, MD: Johns Hopkins University Press, 1987). 
representations the holocaust: "It relies on neoclassicist principles of compositional unity, motivation, linearity, equilibrium, and closure-principles singularly inadequate in the face of an event that by its very nature defies our narrative urge to make sense of, to impose order on the discontinuity and otherness of historical experience." 12 To be sure, Hansen's warnings here are not exclusive to Hollywood storytelling but could be extended to any narrative representation of the past that relies on the conventions of the "well told tale."

\section{Ambiguous Reference and the "Sleeper Effect"}

I previously claimed that there are at least three keys to the power of historical fiction in forming collective memory. The first is the hybrid nature of the historical fiction film; it rides the fence between fiction and nonfiction. Since it occupies a liminal space, audiences will be uncertain about whether to take the film as history, fiction, or some hybrid of the two. Such ambiguity is sometimes highlighted by film techniques, such as the mixing of archival footage with reconstructed footage designed to appear to be archival. This technique was famously used in Oliver Stone's JFK (1991), about the assassination of US president John F. Kennedy. Stone combines the Zapruder film, the only known footage of the actual assassination, with staged footage shot on Super-8, $16 \mathrm{~mm}$, and video, designed to appear to be authentic. As I write elsewhere, this "makes it impossible for the typical viewer to discriminate between reenactments and archival material." ${ }^{13}$ Similarly, at the end of Selma, DuVernay mixes archival footage of the march with reconstructed black and white footage that appears to be archival.

When we view a standard nonfiction film, we expect that the film is presented to us as what I have elsewhere called an "asserted veridical representation." ${ }^{14}$ This term simply means that audiences expect that the typical documentary is presented as a discourse through which the filmmakers make truth claims about the film's subject ${ }^{15}$ and/or provide images and sounds that are presented as reliable guides to that subject. ${ }^{16}$ However, audiences typically make no such assumptions about fiction. Fictional events are imaginary events. They may refer to the actual world but when they do, they do so through metaphor or analogy. We understand that there is no actual Luke Skywalker, no droids

12. Hansen, "Schindler's List Is Not Shoah," 205.

13. Carl Plantinga, Rhetoric and Representation in Nonfiction Film (Cambridge: Cambridge University Press, 1997), 23.

14. Carl Plantinga, "What a Documentary Is, After All," Journal of Aesthetics and Art Criticism 63, no. 2 (Spring 2005): $105-17$.

15. Filmmakers explicitly or implicitly make claims about the subject represented in the film through voice-over narration, editing patterns, intertitles, framing, musical underscoring, or any of the other registers of film style.

16. In other words, the moving photographic images presented by the filmmaker do not necessarily embody clear propositional claims but are sometimes designed to show what something looked or sounded like. This would be a case of "showing" rather than "telling." Documentaries often involve both showing and telling simultaneously. 
Plantinga Collective Memory and the Rhetorical Power of the Historical Fiction Film

like R2-D2, and no nefarious Death Star even though these represented entities may refer to the actual world as types or metaphors.

With regard to historical fiction, however, the boundaries between fiction and nonfiction become quite porous. It is precisely this ambiguity that can impact collective memory. For many viewers, the vivid images and emotional effects of historical fictions seep into their storehouse of memories and images regarding the film's subjects such that aspects of these stories, rightly or wrongly, become prosthetic memories, as Angela Lansberg would say.

Empirical research tends to bear this out. In fact, it may not matter so much if audiences take historical fictions to be mostly fictional rather than accurate historical accounts. Psychologist Jeffrey Zacks, in his book Flicker: Your Brain on Movies, argues that the persuasive effect of stories holds for both fiction and nonfiction. Zachs writes: "When we experience a story, our default is to accept what it tells us as true. We have to do extra work to override that default and question what we are reading. Rather than needing to suspend disbelief, we have to engage in a willing construction of disbelief in order to keep the story world from infecting our real-world beliefs and attitudes." ${ }^{17}$ In other words, Zacks holds that it takes a conscious effort to prevent fictional representation from influencing our beliefs about the world. When one considers the ambiguous status of historical fiction in relation to the historical record-it is based on a "true story," after all-the easiest pattern of response is to file the narrative account into memory as plausible.

Later on, that plausible account may become a prosthetic memory of the past through what psychologists call the "sleeper effect." ${ }^{18}$ The influence of a narrative may actually increase over time as viewers forget the source of their memories about historical events depicted in a historical fiction. In other words, our ideas and images regarding the historical march from Selma to Montgomery, as Landsberg might say, may in large part derive from our viewing of the film Selma, but viewers will often forget the source of their ideas and images. Given many viewers' uncertainty about whether to take the historical drama as history or fiction, it is likely that some will unwittingly take the drama as history. Zacks claims that these processes occur without the conscious knowledge of viewers and independent of the viewer's intentions.

This claim has interesting parallels to claims about mainstream film viewing promulgated by the apparatus theory that held its grip on film and media studies in the '70s and '80s. These theories melded Althusserian Marxism, Lacanian psychoanalysis, the critical theory of Theodor Adorno and Max Horkheimer, and Bertolt Brecht's writings

17. Jeffrey M. Zacks, Flicker: Your Brain on Movies (Oxford: Oxford University Press, 2015), 108.

18. Zacks, Flicker, 101. 
on the alienation effect and epic theater. ${ }^{19}$ Elsewhere I call these estrangement theories because they all critique mainstream narrative, finding it to be stultifying and mystifying for viewers, and propose the elicitation of various sorts of reflexive and alienated spectator responses as an antidote. ${ }^{20}$

I would argue that apparatus theory exaggerated the passivity and mystification ostensibly caused in viewers by classical storytelling and thus was too quick to reject mainstream films as ethically dismissable. ${ }^{21}$ Yet both apparatus theory and contemporary media psychology share the hypothesis that mainstream stories on screens are often highly persuasive and ideologically powerful in their effects. And both point to film medium itself as a source of that power.

\section{Medium Specificity and Immersion}

Is there something about the film medium that makes it particularly powerful as a way to form, sediment, and/or alter collective memory? First and most obviously, film is a mass medium. Screen stories can be easily mass produced, copies or screenings widely disseminated via several distribution platforms or screened before large audiences. Although box office figures are an imperfect measure, we can partly gauge the impact of historical fictions by noting their box office and thus their popularity. The 2012 biopic Lincoln, about Abraham Lincoln and the passing of the 13th Amendment to the US Constitution (which made slavery unconstitutional), grossed over $\$ 275$ million worldwide. The 2000 film Erin Brockovich, about a single mom who nearly brings down a polluting power company, brought in \$256 million, and the 1995 account of a space voyage, Apollo 13, brought in $\$ 353$ million in worldwide box office gross. ${ }^{22}$

The kind of experience provided by the medium of historical fiction films is also key to their power. Many have noted that a movie is something like a representation of human conscious experience. As Oliver Sacks writes, a movie, "with its taut stream of thematically connected images, its visual narrative integrated by the viewpoint and values of its director, is not at all a bad metaphor for the stream of consciousness itself." ${ }^{23}$ It goes without saying that when we remember the past, we are having a kind of conscious experience; it is also often visual and sometimes sonic in nature. Perhaps a movie approximates the experience of remembering, albeit in a hyper-coherent, clarified form. It

19. For an overview of apparatus theory, see Robert Stam, Film Theory: An Introduction (Malden, MA: Blackwell, 2000), 140-92.

20. Carl Plantinga, Screen Stories: Emotion and the Ethics of Engagement (Oxford: Oxford University Press, 2018), 99-116.

21. For an extended argument of this point, see Plantinga, Screen Stories, 97-134.

22. All figures from Box Office Mojo, "Home," Box Office Mojo, accessed June 2, 2020, https://www.boxofficemojo.com/.

23. Oliver Sacks, "In the River of Consciousness," New York Review of Books, January 15, 2004, 41. 
is worth noting that this film experience, an experience that in its appeal to perception and the senses mimics human consciousness itself, is also embodied and emotional. As I will detail later on, the affective nature of film spectatorship is a key to the power of historical narrative film.

The presentness of the experience of a film is also sometimes cited as a factor in its power to create collective memory. Those who teach about film know that when students write about films, they often refer to the film in the past tense, as though it were a thing of the past. Students may write, for example, that the film "was beautiful" or "had a stunning soundtrack." Although the film obviously continues to exist, their experience of the film becomes a part of their past lives, a part of their storehouse of memories. Thus, it is easy to equate that experience, which occurred in the past, with the film itself. Anton Kaes writes that films can represent historical events with a "presentness" that is peculiar to the medium. Film and television, he writes, have become "institutional vehicles for the shaping of public consciousness. They are powerful because they can make history come alive more readily than commemorative addresses, lectures, exhibitions, or museums; they can resituate past events in the immediate experience of the viewer." ${ }^{24}$

As many have observed, this sort of storytelling not only exhibits presentness but also immersiveness. Discussions of immersion and its implications, of course, were central in film studies in the seventies and eighties, at the height of the influence of the apparatus theory mentioned previously. Mainstream films, including historical fiction films, follow conventional story patterns that attempt to elicit absorption, fascination, rapt attention, and immersion. ${ }^{25}$ Sigmund Freud thought that such immersion, in the case of literature at least, was beneficial to the individual, since it leads to the release of tensions and allows us to experience "our daydreams without reproach or shame."26 Apparatus theories, on the other hand, are much less sanguine about the effects of immersion, finding immersion to be a hegemonic process that results in mystification and passivity. ${ }^{27}$

Once again, we find that contemporary media psychology aligns with apparatus theory in that both see the immersive nature of the film experience as key to its persuasive power. Media psychologists tend to call this immersive capacity "psychological transportation." With regard to the persuasive effects of fiction and dramatic documentaries, viewers or readers immersed in a story are more likely to experience belief change than those who are not. Immersed viewers or readers are less likely to notice "false notes" or inconsistencies in the narrative and more likely to endorse beliefs implied by the narrative. ${ }^{28}$

24. Anton Kaes, "History and Film: Public Memory in the Age of Electronic Dissemination," History and Memory 2, no. 1 (Fall 1990): 114, 112.

25. A summary of these arguments can be found in Stam, Film Theory, 140-58.

26. Sigmund Freud, "The Relation of the Poet to Daydreaming," in Creativity and the Unconscious [editor?] (New York: Harper \& Row, 1958), 44-54.

27. Plantinga, Screen Stories, 117-19.

28. Melanie C. Green and Timothy C. Brock, "In the Mind's Eye: Transportation-Imagery Model of Narrative Persuasion," 
Immersion, together with the ambiguous status of historical fiction, may well constitute an especially powerful tandem. When I read a political tract or listen to a political speech that is discrepant with my beliefs, I engage in counterarguing, or, in other words, I consciously find ways to dismiss the claims being made. Based on social scientific research, Michael Slater argues that the spectator's immersion in a narrative inhibits counterarguing and other forms of potential resistance to whatever the story is attempting to promote. Slater claims that due to their capacity to bypass "biased processing" in viewers, the use of narratives may be one of the only tools available to those who wish to persuade people to alter previously held perspectives. ${ }^{29}$ It isn't clear whether historical fictions inhibit counterarguing since their referents are often actual historical events, often with politically contested meanings. Yet it is plausible to speculate that the immersion encouraged by the films often discourages counterarguing and critical response. As we will see, it is the ordering of events in the well-told tale, or the conventional narrative, that facilitates spectator immersion.

\section{Narrative, Emotion, and Ritual}

As various psychologists have argued, collective and individual memory formation are analogous processes that occur on different levels. ${ }^{30}$ According to Maurice Halbwachs, who is credited with introducing the idea of collective memory, we reconstruct our individual memories according to the attitudes and customs of the groups of which we are a part. "It is in this sense," writes Halbwachs, "that there exists a collective memory and social frameworks for memory; it is to the degree that our individual thought places itself in these frameworks and participates in this memory that it is capable of the act of recollection." 31

What are some of the features of this interface between individual and collective memory? What are some of the social frameworks for memory of which Halbwachs writes? Storytelling in multiple media, and conventional story structures in particular, function as one of the chief conduits between personal and collective memory. The conventional narrative is not simply about structuring information; it also structures

in Narrative Persuasion: Social and Cognitive Foundations, eds. Melanie C. Green, Jeffrey L. Strange, and Timothy C. Brock (Mahwah, NJ: Lawrence Erlbaum, 2002), 315-41. Also see Zacks, Flicker, 108.

29. Michael Slater, "Entertainment Education and the Persuasive Impact of Narratives," in Narrative Impact: Social and Cognitive Implications, eds. Melanie C. Green, Jeffrey L. Strange, and Timothy C. Brock (Mahwah, NJ: Lawrence Erlbaum, 2002), 173-75.

30. Thomas J. Anastasio, Kirsten Ann Ehrenberger, Patricks Watson, and Wenyi Zhang, Individual and Collective Memory Consolidation: Analogous Processes on Different Levels (Cambridge, MA: MIT Press, 2012), 1-2.

31. Maurice Halbwachs, On Collective Memory, ed. and trans. Lewis A. Coser (Chicago: University of Chicago Press, 1925/1992), 38. 
an embodied experience that consists of moods and emotions. ${ }^{32}$ It promises drama, suspense, rising action, and climactic resolutions, all of which have the capacity to organize memory and sediment it through powerful affective responses.

Schemas, the generalized frameworks that organize knowledge and aid recall, have long been recognized as important in the formation of memory. One of the dominant schemas for collective memory is the conventional narrative, which in film largely takes the form of what David Bordwell and others have called the classical Hollywood narrative. ${ }^{33}$ Certain psychological factors make this sort of narrative a powerful means of forming and preserving collective memory. Most important, people are more likely to remember emotion-arousing events than neutral, everyday events. ${ }^{34}$ Thus the well-told tale, in the form of a vivid and dramatic historical fiction, is an apt vehicle for the formation and preservation of the collective memories of individuals.

The classical narrative is expressly designed to elicit powerful emotions. ${ }^{35}$ It features a goal-oriented protagonist, conflict, rising action, and a focus on a dramatic conflict and resolution. It isn't simply that the classical narrative, with its familiar structuring of information, forms a mental map onto which new information can be placed. The classical narrative is not merely a schematic structure for the structuring, conveyance, and remembering of information. It is also means of eliciting strong emotions that facilitate memory uptake and preservation. The purpose of eliciting emotion is to provide viewer pleasure; the effect of eliciting emotion is to impact memory.

One can find out much about the ideology of a historical fiction by how it fits historical events into the familiar framework of classical narrative form and the degree to which it does so. Lincoln, Selma, BlacKkKlansman, and Just Mercy, it should be mentioned, feature sympathetic, goal-oriented heroes who face strong obstacles as they pursue their righteous goals. The sympathy and the goals provide an avenue for spectator desire; spectators desire the goals to be achieved. Obstacles to those goals elicit suspense, fear, relief, and other strong emotions (or release from emotion).

In this regard, the climax and resolution of any narrative structure is a focal point through which one can gauge its primary ideological effect. The climactic point of the Lincoln narrative, for example, is the passage of the 13th Amendment to the US

32. I develop a theory of the emotional power of movies in Moving Viewers: American Film and the Spectator's Experience (Berkeley: University of California Press, 2009).

33. David Bordwell, Janet Staiger, and Kristin Thompson, The Classical Hollywood Cinema: Film Style and Mode of Production to 1960 (New York: Columbia University Press, 1985); David Bordwell, Narration in the Fiction Film (Madison: University of Wisconsin Press, 1985).

34. Sven-Ake Christianson and Martin A. Safer, "Emotional Events and Emotions in Autobiographical Memories," in Remembering Our Past: Studies in Autobiographical Memory, ed. David C. Rubin (Cambridge: Cambridge University Press, 1995), 219.

35. Carl Plantinga, Moving Viewers, 78-111. 
Constitution; the film pegs its celebration of Abraham Lincoln as an American hero onto this focal point and climax. The climactic point of Selma is a rousing speech given by Martin Luther King Jr. after he successfully leads a civil rights march from Selma to Montgomery, Alabama; the film pegs its celebration of Martin Luther King Jr. as an American hero onto this focal point and climax. Thus collective memory, to the extent that either of these films contributes to it, is established in a context that first relies on a powerfully affective spectator experience, an experience that is both cognitive and embodied. The emotions elicited by these films are not free-floating feelings but elicited in support of the films' particular perspectives.

British social anthropologist Paul Connerton, in his book How Societies Remember, singles out ritual ceremonies and body practices as essential in the formation and preservation of cultural memory. Ritual ceremonies such as patriotic holiday celebrations, public funerals, parades, and football halftime celebrations and body practices such as singing, chanting, responsive readings, marching, and saluting are means by which "memory is sedimented, or amassed, in the body." ${ }^{36}$ Connerton draws his inspiration in part from Maurice Halbwachs. Halbwachs, as I previously mentioned, thought that it is through membership in a social group that individuals are able to acquire, localize, and recall their memories. We situate what we recollect within the mental spaces provided

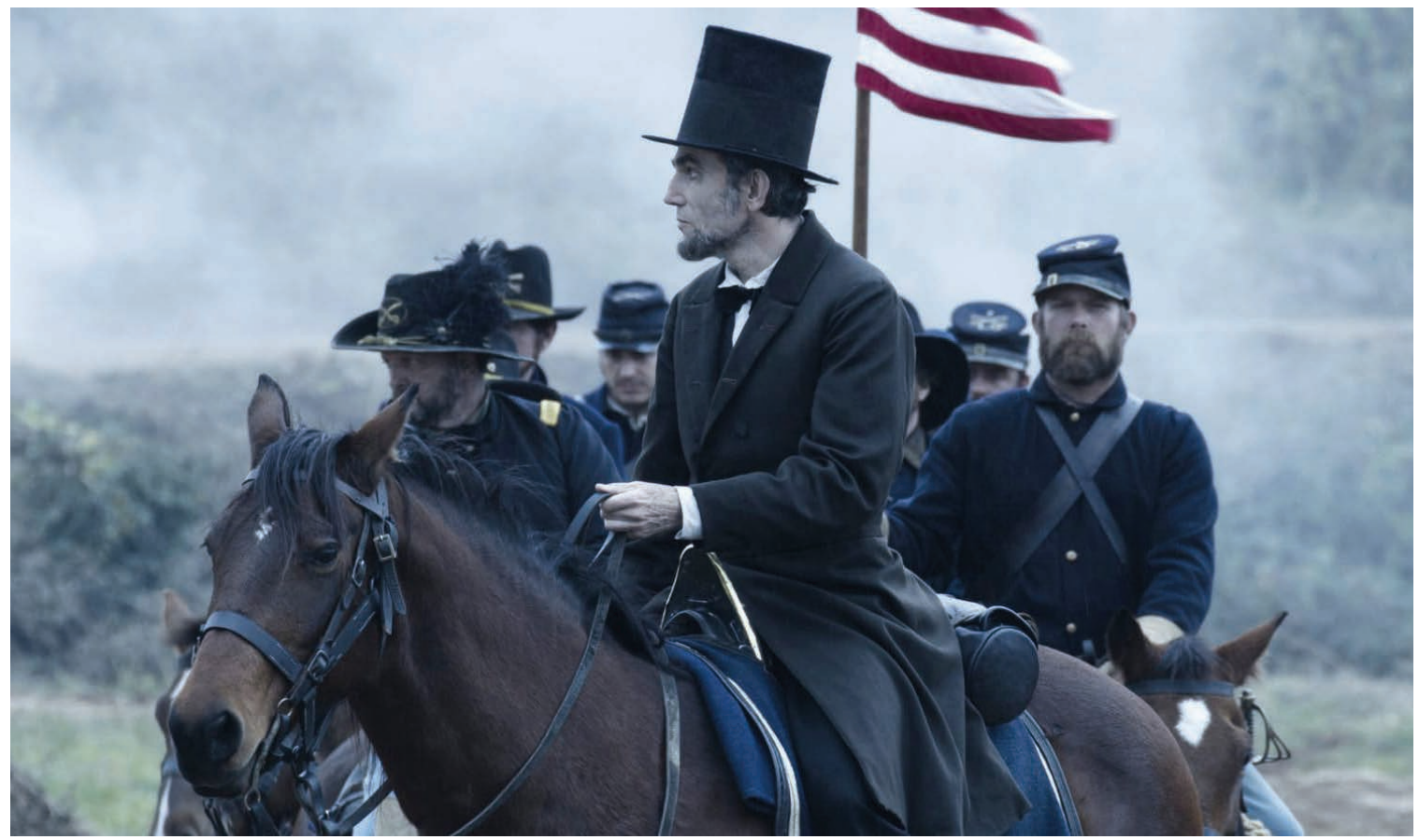

Figure 7.2: Abraham Lincoln (Daniel Day Lewis) in Lincoln (2014). Source: fair use.

36. Paul Connerton, How Societies Remember (Cambridge: Cambridge University Press, 1989), 72. 
by the group. By extension, then, collective memories are solidified, or sedimented, through collective rituals and body practices.

Historical documentaries often depict such collective rituals and body practices in their accounts of historical events and thus offer the spectator a kind of virtual or once-removed ritualistic experience that replicates the sights and sounds such rituals offer. In Lincoln, as I have mentioned, the passage of the 13th Amendment becomes the dramatic climax of the film. After the amendment passes, watchers are shown ritual celebrations that form spontaneously, improbably within minutes of the congressional action. Church bells ring. The members of Congress break into a loud chorus of the "Battle Cry of Freedom," which morphs into a swelling musical underscoring (with more voices and orchestral accompaniment) as the scene cuts to parades of celebrants outside the Capitol Building. The passage of this amendment is ritually shown to have national significance because the rousing music champions the growing crowds of celebrants that the film depicts.

In Selma, as I mentioned, the climax comes with the completion of the civil rights march from Selma to Montgomery, a fifty-mile march of twenty-five thousand people that, according to the film, leads to the passage of national voting rights legislation. Post-march, we see King, one of the finest orators of his time, delivering his famous "How Long? Not Long" speech. DuVernay intermixes reconstructions of the march that use actors and CGI special effects, with black and white archival footage of the actual march. This clearly signals to the viewer that the film represents history, not fiction. As we hear the voice of King (played by David Oyelawo) give his famous speech, the film cuts to various cross sections of the United States - the bystanders of the march and counter protesters. The march ends at the foot of the Alabama State Capitol building, a symbolic gesture and fitting for the ritual celebration of the progress the march has engendered. As the film cuts to close-ups of members of the entire nation listening in (including President Johnson and governor George Wallace), titles show us their futures and relate what we have seen to present times. The ritual speech and its presentation expand outward from Montgomery, Alabama, to the entire nation.

Historical fictions often represent national or other group rituals that are put into a collective meaning structure. But one might claim that historical fictions themselvesin their repetition of common dramatic patterns such as rising action, climactic confrontation, escalating suspense, resolution, and relief — enact a ritual in each instance of their viewing. The body practices they involve have less to do with marching or chanting than with a viewing experience and intended structure of feeling that is replayed again and again and, in some cases, millions of times. ${ }^{37}$ This is a structure of feeling into

37. The term structure of feeling is borrowed from Raymond Williams. Structures of feeling, or emotive scripts, circulate in a culture; filmmakers draw from these to focus a film emotively. For more on structures of feeling, see my Screen Stories, 67-69 and 164-65. 
which historical events are molded into place and through which cultural mythologies and collective memories are preserved, amassed, and passed on.

If a museum is a collective memory structure through which one walks, a historical fiction film is a collective memory structure before which one sits, watches, and listens. That sitting, watching, and listening constitutes a cultural ritual in which national mythologies, inspirational tales, and warnings against folly are replayed and repeated to mass audiences. As Marita Sturken writes, "Cinema is a particularly powerful tool in the incitement of desire and the fantasy of history precisely because of the classic ways in which it invites us to view the past as if we were there. The apparatus of cinema provides the spectator with an experience of the past, one of duration, identification, and emotion, of both anxiety and pleasure." ${ }^{38}$ Historical fictions fit history into neat narrative formulas and elicit powerful emotions that solidify valuations of those historical accounts. Each viewing becomes a kind of ritual experience.

\section{The Implications of Historical Fiction}

So far, I have made the case that mainstream historical fiction films have the capacity to form, consolidate, and/or change cultural memory in part due to their medium and to the kind of emotionally powerful experiences they offer viewers. This raises the obvious question of whether such films are to be feared or welcomed, dismissed as shallow hegemonic tools of the powerful or celebrated for their beneficial effects.

My own position, which is somewhat similar to that of Landsberg, is that mainstream historical fiction films have potential benefits but that this determination needs to be made on a case-by-case basis and always in historical context. Before I make this case, however, let us first examine the more pessimistic accounts of the effects of historical fiction films. The apparatus theories I mentioned previously embodied a deep distrust of mainstream storytelling generally. Some of the critiques of historical fiction emerge from this generalized position and hold that mainstream films are epistemically mystifying and psychologically stultifying. They ostensibly encourage a passive spectatorship.

Mass media portrayals of history are seen by various scholars to have the effect of homogenizing audiences and controlling popular memory. To take one prominent example, Michel Foucault fits the historical fiction film into an overall theory of hegemony, claiming that in the struggle over popular memory, the historical fiction film is a tool of the powerful. He sees television and film as ways of "reencoding popular

38. Marita Sturken, "Reenactment, Fantasy, and the Paranoia of History: Oliver Stone's Docudramas," History and Theory 36, no. 4 (December 1997): 72, 73. 
memory," showing people not what they actually were but rather "what they need to remember themselves as having been." Historical fiction film becomes an essential tool of the hegemon. As Foucault notes, "If you are in charge of the memory of the people, you are in charge of their vitality." 39

This position, however, seems to assume a monolithic system in which the voices of media are wholly controlled by a unified hegemonic force. Are these "dangerous" ideological forces responsible for Selma, BlacKkKlansmen, Just Mercy, and Malcolm X (1992)? And, if so, should these mainstream historical fiction films be dismissed as mystifying tools of the powerful? At the time of this writing, protests are spreading across the United States and elsewhere, demanding an end to racism and especially police brutality against African Americans. During a time when racial tensions threaten the very fabric of US culture, would it be wrong to welcome a collective memory that recognizes racism in this culture and puts civil rights movements and antiracism firmly at the center cultural memory?

Another criticism of the historical fiction film has to do with the very possibility of adequately representing the past. Historical fiction films sometimes imply that there is one neat historical account that we call history, neglecting the essential messiness, ambiguity, and mystery of the past. Documentary scholar Bill Nichols writes of the "magnitudes that exceed any text," meaning that no textual representation could possibly "capture" or fully represent the fullness of history. ${ }^{40}$ For that reason, any narrative that presents a single linear thread with clear plot points and closure surely misrepresents not only its particular historical topic but the nature of history itself. Thus, Nichols advocates certain textual features that counter these errors, such as the open text and open ending, a willingness to embrace contradiction and ambiguity, the recognition of counter narratives, and self-reflexivity. Nichols argues that an "awareness of the tension between representation and that which is represented, of magnitudes beyond representation, is the foundation for praxis informed by a text." ${ }^{11}$

Specifically in regard to the historical fiction film, several film scholars embrace perspectives similar to this. Anton Kaes writes that mainstream historical fictions "colonize the audience's historical imagination instead of liberating it." ${ }^{2}$ Kaes, like many other intellectuals, favors films such as Shoah (1985) because director Lanzmann realizes that the past cannot be fully represented and acknowledges this throughout the film. Paula Rabinowitz, likewise, argues that Shoah is a "powerful and revolutionary film" because it recognizes the partial nature of historical truth, deconstructs the forms

39. Michel Foucault, Patrice Maniglier, and Dork Zabunyan, "Film, History, and Popular Memory," in Foucault at the Movies, trans. and ed. Clare O’Farrell (New York: Columbia University Press, 2018), 106.

40. Bill Nichols, Representing Reality: Issues and Concepts in Documentary (Bloomington: Indiana University Press, 1991), 229-33.

41. Nichols, Representing Reality, 233.

42. Kaes, "History and Film," 118. 
and conventions of the historical film, and interrogates the very notion of historical memory. Marta Sturken, similarly, celebrates Oliver Stone's JFK for the way it so obviously mixes fact and fantasy, the real and the imaginary, and makes no attempt to present itself as history. The fact that it "flaunts its fantasies" is what makes JFK ethically laudable, she claims, because it "interrupts any notion that history can be told outside of fantasy-the fantasy of knowing what really happened, what people were really thinking, what took place, and what could have been." ${ }^{43}$ Certainly films that question the notion of a simple history or truth, such as Jill Godmilow's Far From Poland (1984), Chris Marker's San Soleil (1983), and Trinh T. Minh-ha's Surname Viet Given Name Nam (1989), have a place in a strategy to encourage creative, reflective spectatorship.

Despite all this, I wonder if we should or even can give up on the idea of representing the past though conventional narrative structures and styles such as those we find in classical Hollywood cinema. Or another question: Should the inadequacy of narrative in representing the past in all of its complexity negate the value of creating a cultural memory that unifies a people in relation to common values, responses, principles, and symbols? After all, once we deconstruct, critique, and pull apart, we need to reconstruct something around which people can rally. No ethics or politics can be based on pure negation. Critique must eventually give way to affirmation. It strikes me that films such as Selma, even with their historical imperfections and their limitation to a single antiracist perspective, are right to construct a cultural memory rooted in the goodness of the civil rights struggle. Moreover, a film such as Lincoln, which makes the passage of the 13th Amendment a centerpiece of its dramatic movement, is arguably right to focus on the centrality of that amendment to what the United States hopes to be, or should hope to be.

Given that I have elsewhere argued for "an ethics of engagement," 44 it should come as no surprise that I harmonize with Landberg's more sanguine estimation of the ethics and politics of the historical fiction film and of what she terms "prosthetic memory." Landsberg counts film among the "experiential" mass-mediated forms that can serve as the basis for "mediated" collective identification that has the potential to shape a person's subjectivity and politics. She recognizes that the sensuous, embodied nature of film spectatorship is central to the power of the medium since, as she puts it, memory "remains a sensuous phenomenon experienced by the body" and it derives much of its power through affect. ${ }^{45}$ She finds that historical fiction films, and indeed mass culture generally, have the potential for an opening up or sharing, to promote empathy, and to

43. Sturken, "Reenactment Fantasy," 79.

44. Plantinga, Screen Stories.

45. Landsberg, Prosthetic Memory, 8. 
make "group specific memories available to a diverse and varied populace." ${ }^{46}$ One could certainly make this case in relation to recent historical fiction films such as Selma and Just Mercy, which can potentially introduce audiences to elements of black history and perspectives that they were previously unfamiliar with.

I would also argue that historical fictions such as BlacKkKlansman not only have the potential to elicit empathy for those who feel the brunt of racial discrimination but also incorporate various neo-Brechtian techniques that encourage audience reflection. Elsewhere I have argued that perhaps the best strategy in this regard would be to combine mainstream storytelling conventions designed to fascinate and move audiences, with various formal devices and uses of content that encourage reflective spectatorship. ${ }^{47}$

BlacKkKlansmen, I argue, is an example of what Miriam Hansen would call "popular modernism." While very entertaining and able to attract large audiences, it features the dialectical movement so favored by Brecht. It uses reflexive techniques, highlighting the history of racist representation with clips from The Birth of a Nation (1915) and

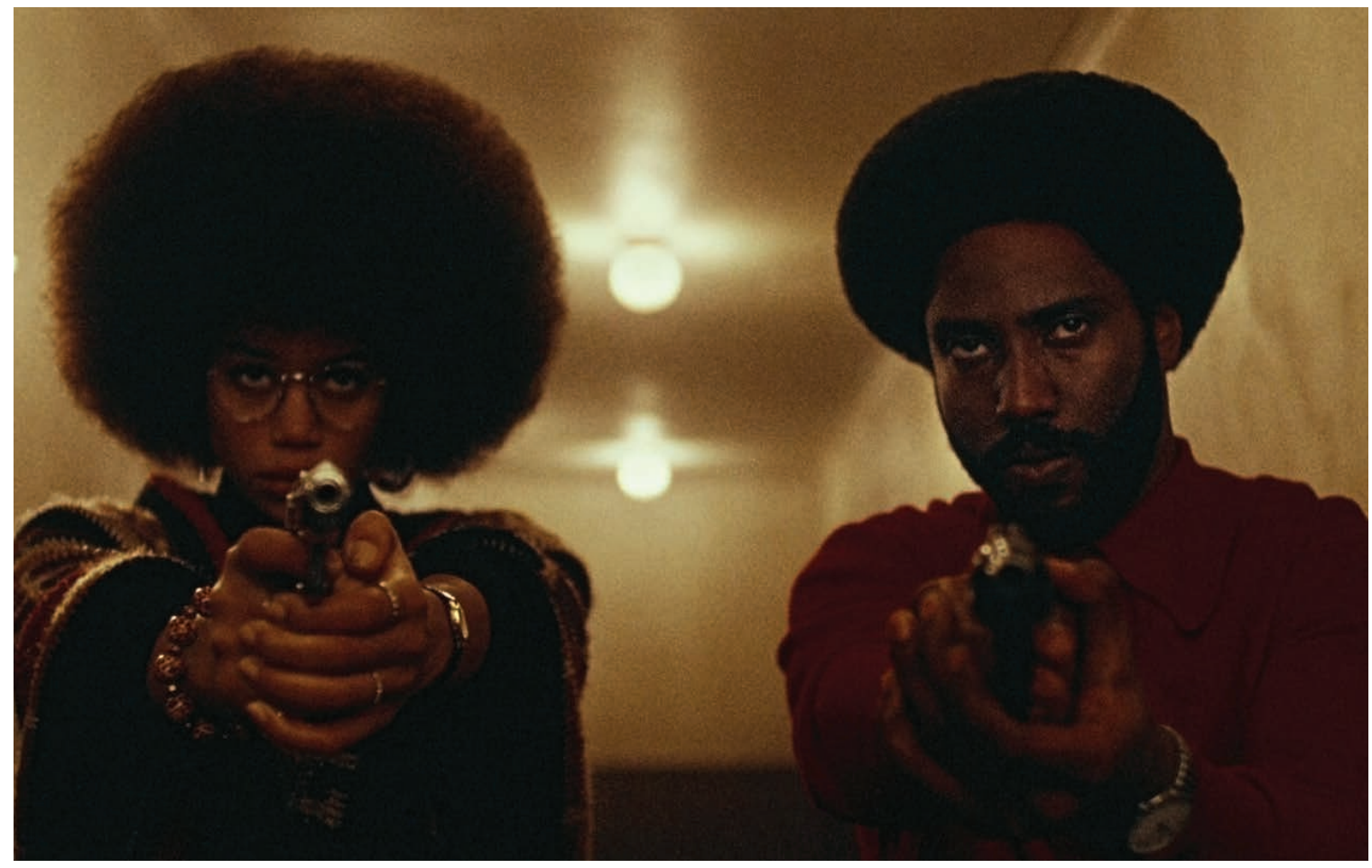

Figure 7.3: Ron (John David Washington) and Patrice (Laura Harrier) approach the camera near the end of BlacKkKlansman (2018). Source: fair use.

46. Landsberg, 11.

47. See Carl Plantinga, "Brecht, Emotion and the Reflective Spectator: The case of BlacKkKlansmen," NECSUS: European Journal of Media Studies 8, no. 1 (2019): 151-69. 
Gone with the Wind (1939), all during an opening scene featuring Dr. Kennebrew Beauregard (Alec Baldwin), a fictional character apparently providing voice-over for some kind of promotional film for an unnamed racist organization. BlacKkKlansman features political speeches from contradictory political perspectives, often putting the spectator into the position of the audience through frontal framing that is almost confrontational in its directness. The film also mixes fictional and newsreel footage, as it ends with a transition from its narrative thread to newsreel footage of the various Unite the Right groups marching in Charlottesville, Virginia, and Donald Trump's claim that there are "good people" on "both sides." BlacKkKlansmen is yet another example of the "compulsive pas-de-deux," as Andreas Huyssen puts it, that has characterized modernism and mass culture since the mid-nineteenth century. ${ }^{48}$

\section{Conclusion}

The historical fiction film is a form of global storytelling with the potential for significant influence in the formation, consolidation, and/or alteration of collective memory. Thus, the historical fiction film will often be at the center of struggles to define a nation or other social group. I have argued that historical fictions have important features that make them effective in their function. They play on the sleeper effect and an ambiguous reference to reality in their storytelling. They take advantage of the presentness of the medium and the capacity of the classical Hollywood structure to immerse audiences, inhibit counter arguing, and thus persuade. The experience of viewing a historical fiction film is of course embodied and, when it does its work successfully, suffused with affect. All of this contributes to its potential to impact the collective memory of viewers and of a culture.

From an ethical perspective, what can we legitimately expect from a historical fiction film? Such a film is neither history nor journalism, and so it seems inappropriate to demand strict fidelity to the historical record, at least in regard to the less relevant events or details. I would argue, however, that as ethical critics, we can advocate for at least two things. The first is a form that invites critical thinking on the part of audiences. This should not mean the wholesale rejection of mainstream conventions of storytelling. Although reflexive and formally difficult films may in fact encourage critical thinking, they tend to appeal to a rarefied audience and one that is in many cases already in agreement with the sort of political position taken up by the film. Films that offer both mainstream appeals and modernist, reflection-inducing techniques may be the

48. Andreas Huyssen, After the Great Divide: Modernism, Mass Culture, Postmodernism (Bloomington: Indiana University Press, 1986), 24. 
best strategy. BlacKkKlansman, as I have argued, is an example of such a film. It is not solely a work of estrangement or alienation but a work of engagement. Judging from its simultaneous box office and critical success, it fascinates and moves many viewers emotionally. It encourages rapt attention and immersion. It encourages strong sympathies and antipathies for characters. Yet it also provokes and elicits questions through contradiction, dialectics, interruption, and political content.

Second, the critic should inquire whether a historical fiction film will make an ethical contribution to the collective memory of a particular culture at a particular time. Granted, what ethical means in this case will be both contested and subject to a variety of interpretations. The fact that what is ethical or beneficial is not easy to define apart from particular historical circumstances should not dissuade us from pursuing it, however. The point is that instead of rejecting what is perceived as mainstream or conventional storytelling in total, we should first examine the contribution a particular screen story is likely to make to collective memory in a particular historical context. What is right for the United States may be wrong for Hong Kong, for example, and vice versa. A historical fiction film may unify a culture by celebrating key events in its past. Or, it might demonstrate how positive change can occur only through decisive action, persistence, courage, and sacrifice, as it is shown to occur in Selma, Just Mercy, BlacKkKlansman, and Lincoln. These are collective memories to be built on. 